46

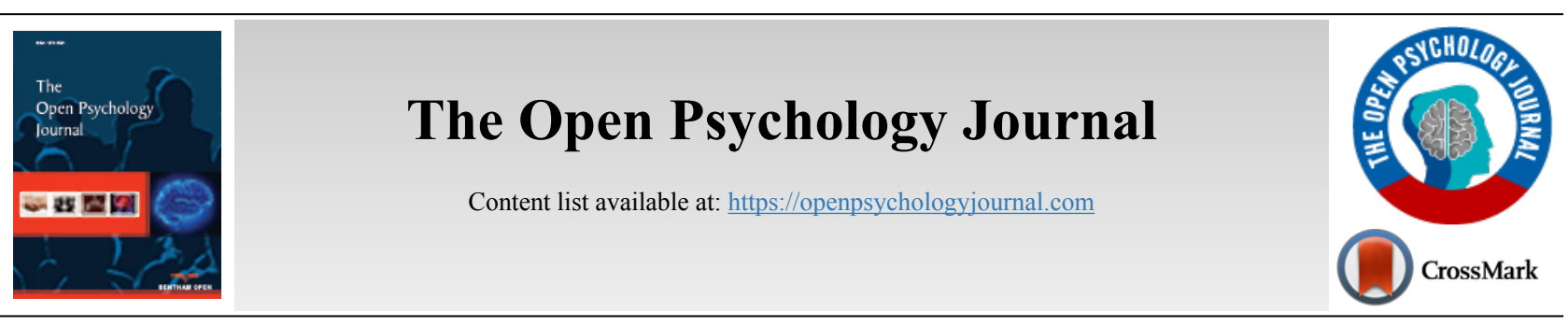

RESEARCH ARTICLE

\title{
Validating the Arabic Scale of Happiness among College Students
}

\author{
Hamzeh M. Dodeen ${ }^{1, *}$ and Brettjet L. Cody ${ }^{1}$ \\ ${ }^{I}$ Department of Psychology, College of Humanities and Social Sciences, United Arab Emirates University (UAEU), Al-Ain, United Arab Emirates \\ (UAE)
}

\begin{abstract}
:
Background:

Happiness is well known to have positive consequences not only on one person but also on society as a whole. For this reason, psychologists have become increasingly interested in positive psychology in general and in happiness in particular. This interest has been reflected in studying happiness and measuring it. Thus, questions raised lately about the best methods or producers and tools to accurately measure it. And, because happiness is a culturally influenced construct, the applicability of such tools needs to be verified across cultures.

\section{Objectives:}

The study aimed at assessing the reliability and validity of the Arab Scale of Happiness (ASH). The study was conducted on college students, and the analysis included testing of several statistical analyses such as the correlations between two tools for measuring happiness, namely, the Oxford Happiness Questionnaire (OHQ) and Satisfaction With Life Scale (SWKS), and Beck Depression Inventory (BDI-II).

Methods:

A total of 731 college students from a public university in UAE were recruited for the tests used in the study. The validation process of the ASH included assessing its factor structure using both exploratory factor analysis and confirmatory factor analysis. Convergent validity, discriminant validity, and internal reliability of the scale were assessed and reported in addition to evaluating gender differences.

Results:

Results indicated that the ASH is unidimensional, with a dominant factor explained more than $50 \%$ of the variance. The internal reliability of the ASH was high $(\alpha=.93)$, and all items performed properly in measuring happiness. The scale has a good convergent validity as it is highly and positively correlated with OHQ and SWLS, and good discriminate validity as its highly and negatively correlated with BDI-II.

\section{Conclusion:}

The ASH is a reliable and valid scale for measuring happiness among youth and college students. It is necessary to establish its appropriateness for use across populations or countries in future studies. Furthermore, the scale can be used in cross-cultural applications to assess happiness among different groups of individuals.
\end{abstract}

Keywords: ASH, BDI, SWKS, Happiness, Negative emotions, Cross cultural applications.

\begin{tabular}{l|l|l|l} 
Article History & Received: August 12, 2020 & Revised: December 07, 2020 & Accepted: January 1, 2021
\end{tabular}

\section{INTRODUCTION}

There has been an increasing interest in positive psychology and the science of happiness [1 - 4]. Happiness is one of the main components of positive psychology. Happiness can be defined as the individual evaluation of the overall quality of his/her own life. In other words, how much one likes the life he/she lives [5]. Three components of happiness have been identified in prior research, namely positive emotion, satisfaction, and the absence of negative emotions, such as

* Address correspondence to this author at Department of Psychology, United Arab Emirates University, P. O. Box 15551, Khalifa Road, Al Ain, UAE;

E-mail: hdodeen@uaeu.ac.ae depression and anxiety [6]. Happiness is a comprehensive measure of one's satisfaction with life and a general feeling of emotional well-being. Therefore, measuring happiness scientifically requires accurate scales with good psychometric properties [7].

Related literature indicates that happiness positively affects individuals' productivity, sociability, success in life, work, and family [8, 9]. Happy individuals are more successful across multiple life domains than unhappy ones [10]. Happiness is one of the main goals of modern society; thus, policymakers are interested in societal conditions that promote happiness among individuals [5]. 
There are many international measures or scales of happiness, and several of them are available in Arabic, but most of them have been adapted from Western or American scales. Happiness is a culturally constructed concept [11]."Happiness is not understood as a 'given universal' but is construed culturally bounded and is defined, internalized and socialized accordingly" [12]. Thus, cultural context should be considered while measuring happiness. On the other hand, few happiness scales in Arabic are available for research purposes. These scales have been developed and published in different cultures and languages, which determine their own definition and meaning of happiness. Thus, these scales do not always fit with other cultures and languages.

The Arabic Scale of Happiness [13] is a recent measure of happiness with good psychometric properties. The ASH was constructed and initially validated in the Arabic culture/language using several samples from Kuwait. Thus, it should be better than other measurement tools to assess happiness in young students and adolescents' populations of this culture. Additionally, the scale is relatively short (15 items), which decreases the time and effort of respondents. All items of the scale were simple and positively worded. Finally, ASH showed acceptable high levels of reliability and validity.

This study was set out to assess the validity of the Arabic Scale of Happiness (ASH). Validating the ASH was necessary to ensure its appropriateness for use with different populations or countries before it can be used in future cross-cultural research applications. More specifically, the study aimed to identify the factor structure of ASH and provide additional evidence for the validity and other psychometric properties of this instrument. Although the scale was developed using samples of young students from Kuwait, it is valuable to validate it using samples from similar populations such as college students but from other countries. This can be considered as cross-validation of the scale since it has not been validated after it was originally developed. In addition, this can open the door to use the scale with different segments of Arab populations in the UAE, such as adults, seniors, nationals, and expatriates.

\section{METHODS}

\subsection{Participants}

College students have been selected and targeted in this study because the ASH was originally constructed and validated to suit college students and adolescents [13]. Additionally, college students have been the target population for many studies of happiness and positive psychology. For example, happiness among college students and related variables were studied by many researchers $[12,14,15]$.

The study was conducted on data obtained from a randomly selected sample of 731students currently enrolled at the United Arab Emirate University (UAEU). UAEU is the first public university in UAE with an enrollment of approximately 14,000 students. Data were conducted during regular classes. Participation was anonymous and confidential. A cluster random sampling methodology was used to select the participants from the university using the class sections as the clusters. A specific number of sections, based on both gender and college, were randomly selected from the list of the offered sections in the university. Data then were collected from all students who are registered in the selected sections. The sample was selected such that it represented all colleges at the university and the two campuses (males and females). The research project and all the scales used on students were approved by the Research Ethics Committee at UAEU. Participants were clearly assured that the collected data are confidential and used for research purposes only.

\subsection{Measures}

\subsubsection{The Arabic Scale of Happiness (ASH)}

The ASH consists of 15 short statements and five filler items. Each item is answered on a 5-point intensity scale (Not at all $=1$, A little $=2$, Moderately $=3$, High $=4$, and Very high $=5$ ). The minimum score on the scale is 15 , and the maximum score is 75 . The total score represents the person's level of happiness, and high scores indicate higher levels of the domain. The author mentioned that the item pool was constructed from three resources: related literature, items from previous similar scales, and personal experience. The initial pool consists of 61 positively worded statements written in modern, simple, and standard Arabic [13].

The internal reliability of ASH measured by Cronbach's alpha and the test-retest reliabilities ranged from .82 to .94 , showing good internal consistency and time-based stability. Three international scales of happiness (Fordyce Happiness Measure, Subjective Happiness Scale, and Oxford Happiness Inventory) were used to assess the construct validity of the scale. The construct validity coefficients ranged from .55 to .79. In another study [14], ASH showed high levels of internal reliability as measured by Cronbach's alpha: .93 for the male sample and .91 for the females. High levels of reliability and validity coefficients of ASH were also observed in other studies $[15,16]$.

The ASH uses only positively worded items, so all the 15 items in the scale were stated in the positive direction of happiness. For example, item 5, "My life has meaning" and item 12, "I enjoy what I do." To control acquiescence response bias, five filler items (items $3,6,8,14$, and 17) were added to the scale. These items are very similar to the rest of the items, except they appear in the negative direction. Examples are: "I am worried," "I feel sad and depressed," and "I am afraid of death." The filler items were not considered as part of any analysis nor in calculating the total score.

\subsubsection{Oxford Happiness Questionnaire}

Oxford Happiness Questionnaire (OHQ) [17] has been derived from the Oxford Happiness Inventory (OHI).OHQ includes 29 items, each measured on a uniform 6-point Likerttype scale that ranges from 1 "strongly disagree" to 6 "strongly agree." Examples of the items are as follows: item 3 "I feel that life is very rewarding," item 15 "I am very happy," and item 25 "I feel I have a great deal of energy." Among the 29 items, 12 items are worded negatively, so their scoring is reversed before calculating the total score of the participant such that the higher 
the score on the scale, the happier the person. QHQ has been translated and used by Arabic populations [18]. Results of this scale in the current study showed that the $\mathrm{OHO}$ has high internal reliability (Cronbach Alpha $=.90)$.

\subsubsection{Satisfaction with Life Scale (SWLS)}

Life satisfaction refers to the quality of one's life. It is related to the affective aspects of subjective well-being status such as happiness, joy, depression, and stress $[19,20]$. SWLS, a commonly used measure of life satisfaction [21], measures total life satisfaction. SWLS consists of 5 items that use a 7point Likert-type response format $(1=$ strongly disagree to $7=$ strongly agree). The minimum score of the scale is 5 , while the maximum is 15 , with higher scores indicating a higher level of life satisfaction. Sample of the scale items are as follows: Item 1 "In most ways, my life is close to ideal" and item 5 "If I could live my life over, I would change almost nothing." SWLS was used in cross-cultural studies and was found to be reliable and valid with varied populations [22 - 24]. Relevant to the present study, SWLS has been adapted and validated in the UAE population [25]. Results of the current study showed that the SWLS has high internal reliability (Cronbach Alpha $=.84$ ).

\subsubsection{Beck Depression Inventory (BDI-II)}

The original BDI was published in 1961 by Aaron Beck and colleagues (BDI) [26 - 31], and the later BDI-II was published in 1996. This widely used scale for measuring depression consists of 21 multiple-choice self-report questions related to symptoms of depression such as mood, pessimism, sense of failure, self-dissatisfaction, guilt, punishment, crying, work difficulty, insomnia, fatigability, loss of appetite, and weight loss. The response to each item in BDI-II is scored on a range between 0 and 3 . The overall scores items are added up together to make a total score, and the higher total scores indicate greater depression. Results of the current study showed that the BDI has high internal reliability (Cronbach Alpha $=.88$ ).

\subsection{Procedure}

A survey package was given to each of the participants. Data were then collected, entered, and checked for missing values and outliers before running any statistical analysis. Demographic information of the participants was calculated first, and it included age, gender, college, and Grade Point Average (GPA). The GPA system used in the UAEU is the unweighted GPA scale in which the highest grade that can be achieved is 4.0, which indicates an A average in all classes. The scale accounts for all classes equally regardless of the class level.

The validation process of the ASH included assessing the factor structure of the scale using both Exploratory Factor Analyses (EFA) and Confirmatory Factor Analysis (CFA). Criterion-related validity (convergent validity) was assessed by examining the correlations between ASH and each of the other happiness measures used in this study (Satisfaction with Life and Oxford Happiness Questionnaire). Discriminant validity was assessed by correlating ASH with Beck Depression Inventory (BDI-II). The internal reliability of ASH and other scales was assessed through the Cronbach alpha coefficient. Finally, gender differences in responses on the ASH were compared. Statistical Package for the Social Sciences (SPSS) was used in analyzing the data.

The common method bias (CMB), which is the measurement error that occurs when the respondents tried to give positive answers [32], was handled by using five filler items (items 3, 6, 8, 14, and 17) in the ASH. These items were negatively worded, so they controlled response bias, which is one main source of CMB. Additionally, the conducting environment of the scale, especially the short time needed for completing the scale and applying it in the classroom setting, helped to reduce any potential CMB.

\section{RESULTS}

Table 1 summarizes the participants' demographic characteristics. It shows that $33.1 \%$ of participants were males, and the rest were females. The eight colleges of the UAEU were represented in this sample. The average age of students was approximately 20 years, with an average GPA of 2.87 .

Participants responded to the happiness items, and the results of the 15 items of AHS are presented in Table 2. As reported, most of the happiness items received a response with above-average scores with similar standard deviation values. The results ranged between 2.64 (item 7) to 4.37 (item 20), which indicates that students are generally feeling happy.

\subsection{Factor Structure}

It has been reported that the unrotated factor analysis of ASH suggested a single factor with high eigenvalues and significant item loadings [13]. To validate these results on the current sample, EFA was implemented to identify the underlining factors of scale. First, the suitability of factor analysis to the current data was examined using Kaiser-MeyerOlkin (KMO) Measure of Sampling Adequacy and Bartlett's Test of Sphericity. The KMO test value was .96 , which is a very satisfactory level (usually values above .70 are acceptable). Bartlett's Test tests the hypothesis that all variables are uncorrelated or have very low correlation values. The results indicated that Bartlett's Test is significant $\left(\chi^{2}=5446.02\right.$, $\mathrm{df}=105, p=.00)$ thus rejecting the null hypothesis. Consequently, both tests confirm the appropriateness of the current data for factor analysis.

An EFA was conducted with two criteria: an eigenvalue greater than 1.00 and an item loading of .40 or above to include the item in the factor. Based on that, it was found that the 15 items of the scale were loaded highly on only one factor. The loading values ranged between .44 and .80 (Table 2). This dominant factor explained $52.21 \%$ of the total variance, which is less than what the developer reported (55.1\%). The unidimensionality of the AHS supports the usage of it as an overall measure of happiness in the current population. 
Table 1. Demographic characteristics of the participating students.

\begin{tabular}{|c|c|c|c|c|c|}
\hline \multicolumn{2}{|c|}{-} & \multirow{3}{*}{\begin{tabular}{|c|}
$N(\%)$ \\
$242(33.1 \%)$ \\
$489(66.9 \%)$
\end{tabular}} & \multirow{2}{*}{\begin{tabular}{|c|} 
Age (mean $[$ SD] $)$ \\
$19.98(1.77)$
\end{tabular}} & \multirow{2}{*}{\multicolumn{2}{|c|}{$\begin{array}{c}\text { GPA (mean[SD]) } \\
2.87(.55)\end{array}$}} \\
\hline \multirow[t]{2}{*}{ Gender } & \multirow{2}{*}{$\begin{array}{c}\text { Male } \\
\text { Female } \\
\end{array}$} & & & & \\
\hline & & & & & \\
\hline \multirow[t]{6}{*}{ College } & & $\begin{array}{c}\text { Humanities \& } \\
\text { Social Sciences }\end{array}$ & Sciences & Business & Education \\
\hline & $\mathrm{N}$ & 152 & 83 & 82 & 61 \\
\hline & $\%$ & 20.8 & 11.4 & 11.2 & 8.3 \\
\hline & & Engineering & Agriculture & Information Technology & Law \\
\hline & $\mathrm{N}$ & 143 & 56 & 75 & 79 \\
\hline & $\%$ & 19.6 & 7.7 & 10.3 & 10.8 \\
\hline
\end{tabular}

Table 2. Means, standard deviations, and loadings of the items of the AHS.

\begin{tabular}{|c|c|c|c|}
\hline Item & Mean & SD & Item factor loading \\
\hline 1. I have an overall sense of wellbeing & 3.72 & 1.05 & .71 \\
\hline 2. I am happy with my lifestyle & 3.67 & 1.09 & .78 \\
\hline 4. I love life* & 3.83 & 1.05 & .70 \\
\hline 5. My life has meaning & 3.90 & 1.13 & .65 \\
\hline 7. I am as happy now as when I was younger & 2.64 & 1.29 & .68 \\
\hline 9. I feel good about my personal life. & 3.67 & 1.08 & .76 \\
\hline 10. My daily life is full of pleasant experiences & 3.21 & 1.12 & .78 \\
\hline 11. I feel relaxed and free from tension & 2.89 & 1.18 & .73 \\
\hline 12. I enjoy what I do & 3.50 & 1.09 & .73 \\
\hline 13. I feel optimistic about the future & 3.78 & 1.16 & .71 \\
\hline 15. I feel full of vitality and energy & 3.21 & 1.14 & .76 \\
\hline 16. I feel that I am successful & 3.56 & 1.05 & .74 \\
\hline 18. I feel that my mental state is excellent & 3.46 & 1.19 & .80 \\
\hline 19. I am satisfied with my life & 3.98 & 1.08 & .78 \\
\hline 20. I have friendly feelings towards other people & 4.37 & 0.89 & .44 \\
\hline
\end{tabular}

*Note: Items 3, 6, 8, 14, and 17 are filler.

To validate the one-factor solution of the ASH obtained from the EFA above, a CFA was conducted. Model fitness was assessed using several fit indices. These indices included the Non-Normed Fit Index (NNFI) and the Comparative Fit Index (CFI). Values of NNFI and CFI ranged between 0 and 1, with a value equal to or higher than .90, indicating a good fit [27]. In addition, the Standardized Root Mean Square Residual (SRMR) and the Root Mean Square Error of Approximation (RMSEA) were examined. Values of SRMR and RMSEA below .08 show a good fit [28, 29]. Furthermore, it was determined that the goodness of fit indexes $(\mathrm{NNFI}=.91, \mathrm{CFI}=$ $.92, \mathrm{RMSEA}=.09, \mathrm{RMR}=.05)$ were sufficient $[30,31]$.

\subsection{Reliability Analysis}

The internal reliability of the ASH was determined to be high $(\alpha=.93)$. In addition, the performance of each of the 15 items was estimated by calculating each item's effect on the scale reliability (Alpha when an item is deleted). The results indicated that the Alpha coefficient did not change. This means that all items of the scale are highly related, working together, and perform appropriately in measuring happiness.

\subsection{Convergent and Discriminant Validity}

In terms of convergent validity, the relationships between the Arabic Happiness Scale (ASH) and each of Oxford Happiness Questionnaire (OHQ) and Satisfaction with Life Scale (SWLS) were calculated. As for discriminate validity, the correlations between ASH and Beck Depression Inventory (BDI-II) were calculated, and all results are summarized in Table 3. It was found that the scale has a good convergent validity as it is highly and positively correlated with OHQ and SWLS. Furthermore, the divergent validity of the ASH scale has been adequately demonstrated through its significant and negative correlation with BDI-II.

Table 3. Demographic characteristics of the participating students.

\begin{tabular}{|c|c|}
\hline- & Arabic Happiness Scale (AHS) \\
\hline Oxford Happiness Questionnaire (OHQ) & $.81^{* *}$ \\
\hline Satisfaction with Life Scale (SWLS) & $.68^{* *}$ \\
\hline Beck Depression Inventory (BDI-II) & $-.57^{* *}$ \\
\hline
\end{tabular}


Table 4. Means and standard deviations of the ash items by gender.

\begin{tabular}{|c|c|c|c|c|}
\hline Item & \multicolumn{2}{|c|}{ Males } & \multicolumn{2}{c|}{ Females } \\
\cline { 2 - 5 } & Mean & SD & Mean & SD \\
\hline 1. I have an overall sense of wellbeing & 3.82 & 1.16 & 3.61 & 1.03 \\
\hline 2. I am happy with my lifestyle & 3.72 & 1.17 & 3.62 & 1.06 \\
\hline 4. I love life & 3.88 & 1.05 & 3.79 & 1.03 \\
\hline 5. My life has meaning & 4.00 & 1.16 & 3.81 & 1.12 \\
\hline 9. I feel good about my personal life. & 2.83 & 1.33 & 2.52 & 1.24 \\
\hline 10. My daily life is full of pleasant experiences & 3.78 & 1.09 & 3.59 & 1.07 \\
\hline 11. I feel relaxed and free from tension & 3.36 & 1.11 & 3.10 & 1.10 \\
\hline 12. I enjoy what I do & 3.01 & 1.27 & 2.82 & 1.12 \\
\hline 13. I feel optimistic about the future & 3.65 & 1.09 & 3.39 & 1.08 \\
\hline 15. I feel full of vitality and energy & 3.74 & 1.22 & 3.75 & 1.15 \\
\hline 16. I feel that I am successful & 3.31 & 1.18 & 3.14 & 1.12 \\
\hline 18. I feel that my mental state is excellent & 3.58 & 1.04 & 3.49 & 1.07 \\
\hline 19. I am satisfied with my life & 3.58 & 1.23 & 3.37 & 1.17 \\
\hline 20. I have friendly feelings towards other people & 4.02 & 1.11 & 3.92 & 1.06 \\
\hline & 4.38 & 0.94 & 4.32 & .900 \\
\hline
\end{tabular}

\subsection{Gender Differences in Happiness}

An additional analysis was conducted to compare the level of happiness between male and female students. The idea behind this analysis is to apply the scale in sub-samples of the same population. The development and validation of the ASH included comparing males and females on their happiness level [13]. Additionally, gender differences are usually interesting information to know in social sciences in general and in psychological studies in particular. As shown in Table 4, males demonstrated higher levels of happiness than females on all items of the scale. To statistically test these results, a t-test was employed using the overall scores of the ASH scale. Results indicate significant gender differences $(t=2.29, p=.02)$, suggesting that males have a higher happiness level than females.

\section{DISCUSSION}

Happiness has positive consequences for both individuals and society. Lately, psychologists have become increasingly interested in studying positive psychology in general and happiness in particular. Like most of the other psychological constructs, happiness is not an easy construct to define nor to measure. Additionally, happiness is a culturally influenced construct, which makes measuring it accurately a valuable goal. Lately, several questionnaires and scales have been developed, validated, and used in assessing happiness in different populations and cultures. The purpose of this study was to establish the validity and psychometric properties of a recently developed scale, which is the Arab Scale of Happiness (ASH). The scale is relatively short, consisted of 15 simple and positively-worded items, which decreases the time and effort of respondents. In the original samples, the scale demonstrated high internal reliability as measured by Cronbach's alpha and high test-retest reliabilities. In addition, the construct validity of ASH coefficients using several international scales of happiness was all high.

The results of the current study provided satisfactory indices of the factor structure and the internal consistency of the ASH. The scale demonstrated strong internal consistency ( $\alpha$ $=.93$ ), and all items were highly and positively correlated with the scale. To test for construct validity, a correlation analysis between the ASH and each of OHQ, SWLS, and BDI-II was carried out to examine the hypothesized relationships among these scales. A significant positive correlation was found between OHQ and SWLS. Both OHQ and SWLS measure happiness or aspects of happiness and are expected to have high and positive correlations with other measures of the same construct. These correlations can be considered as indicators of acceptable convergent validity of the ASH. Depression is synonymous with unhappiness; therefore, the BDI- II negative and significant correlations with the scores obtained from ASH were considered as indicators of acceptable divergent validity.

The findings of this study provided support for the unidimensional factor structure of the ASH scale. The EFA and the CFA results revealed one dominant factor that explained more than $50 \%$ of the total variance. Additionally, all the 15 items of the scale loaded on this dominant factor. In summary, the present study provided strong support for the value of the $\mathrm{ASH}$ as a measure with adequate psychometric properties. Results provided support for the validity and reliability of the ASH scale. Evidence from this study showed that the ASH is psychometrically relevant, has acceptable internal consistency, and a robust unidimensional factor structure.

The comparison between male and female participating students revealed that males are happier than their counterparts' females as measured by the overall scale and each item. This is similar to what has been reported about happiness lately in the UAE $22.81 \%$ of males are very happy vs. $20.1 \%$ of females) [33]. The reasons behind these results can be attributed to cultural factors and differences between the two gender, which can be reflected in the lifestyle of each gender and happiness. However, this needs thorough investigation and analysis, which is not the scope of the current study. 
Happiness is a culturally-related construct in terms of its meaning, predictors, and motivations undelaying it [11]. Thus, measuring happiness should consider the cultural context. ASH was developed and validated within the Arabic culture so it should be better than other measurement tools to assess happiness in populations from similar cultures. From the above illustration, we can conclude that the ASH is a reliable and valid scale for measuring happiness among youth and college students. It is necessary to establish its appropriateness for use across populations or countries in future studies. Therefore, the scale is highly recommended to be used to assess happiness in Arab youth. Furthermore, the scale can be used in crosscultural applications to assess happiness among different groups of individuals. The scale can be used internationally as well as locally. As indicated earlier, the scale is relatively short, simple, and the filler items can control the anticipated response bias. In addition to the original Arabic version, the scale has an English version which can be used for other countries and cultures. At the local level, there is an increase interest in happiness in UAE since it has been considered a very happy country and ranked the 21 st happiest nation in the world and the happiest in the Arab region [34]. Promoting happiness became a strategic goal in the UAE. The country created a ministry for happiness and launched national programs for happiness and positivity. ASH can be used in measuring happiness in this country whether for research studies or for life applications.

\section{CONCLUSION}

Future studies are also suggested to explore the appropriateness of the scale across different groups based on ethnicity, age, gender, and marital status. The limitations of the current study are related to the sample of the participating students. The sample was selected from only one university, which may affect its representation of the target population.

\section{ETHICS APPROVAL AND CONSENT TO PARTI- CIPATE}

This study was approved by the Social Sciences Research Ethics Committee at United Arab Emirates University, UAE under approval no. ERS_2017-5674.

\section{HUMAN AND ANIMAL RIGHTS}

No animals were used in this research. All human research procedures followed were in accordance with the ethical standards of the committee responsible for human experimentation (institutional and national), and with the Helsinki Declaration of 1975, as revised in 2013.

\section{CONSENT FOR PUBLICATION}

Informed consent was taken from all the participants when they were enrolled.

\section{AVAILABILITY OF DATA AND MATERIALS}

The data and materials used to support the findings of this study are available from the corresponding author (H.D) upon reasonable request.

\section{FUNDING}

None.

\section{CONFLICT OF INTEREST}

The author declares no conflict of interest, financial or otherwise.

\section{ACKNOWLEDGEMENTS}

Declared none.

\section{REFERENCES}

[1] Argyle M. The psychology of happiness. London: Methuen 2002.

[2] Aspinwall LG, Staudinger UM. A psychology of human strengths: Fundamental questions and future directions for a positive psychology. Washington, DC. 2003.

[3] Chang EC. Optimism and pessimism: Implications for theory, research, and practice. Washington, DC: American Psychological Association 2001.

[http://dx.doi.org/10.1037/10385-000]

[4] Lopez SJ, Snyder CR. Positive psychological assessment: A handbook of models and measures. Washington, DC: American Psychological Association 2003.

[http://dx.doi.org/10.1037/10612-000]

[5] Veenhoven R. Cross-national differences in happiness: Cultural measurement bias or effect of culture? Int J Wellbeing 2012; 2(4): 333-53.

[http://dx.doi.org/10.5502/ijw.v2.i4.4]

[6] Argyle M, Martin M, Lu L. Testing for stress and happiness: The role of social and cognitive factors.Stress and emotion. Washington, DC: Taylor \& Francis 1995; Vol. 15: pp. 173-87.

[7] Hsee CK, Tang JN. Sun and water: on a modulus-based measurement of happiness. Emotion 2007; 7(1): 213-8. [http://dx.doi.org/10.1037/1528-3542.7.1.213] [PMID: 17352577]

[8] Bardasi E, Francesconi M. The impact of atypical employment on individual wellbeing: Evidence from a panel of British workers. Institute for Social and Economic Research, University of Essex 2003.

[9] Diener E. Subjective well-being. The science of happiness and a proposal for a national index. Am Psychol 2000; 55(1): 34-43. [http://dx.doi.org/10.1037/0003-066X.55.1.34] [PMID: 11392863]

[10] Lyubomirsky S, King L, Diener E. The benefits of frequent positive affect: does happiness lead to success? Psychol Bull 2005; 131(6): 803-55.

[http://dx.doi.org/10.1037/0033-2909.131.6.803] [PMID: 16351326]

[11] Uchida Y, Norasakkunkit V, Kitayama S. Cultural construction of happiness: Theory and empirical evidence. J Happiness Stud 2004; 5: 223-39.

[http://dx.doi.org/10.1007/s10902-004-8785-9]

[12] Moghnie L, Kazarian SS. Subjective happiness of Lebanese college youth in Lebanon: Factorial structure and invariance of the arabic subjective happiness scale. Soc Indic Res 2012; 109: 203-10. [http://dx.doi.org/10.1007/s11205-011-9895-5]

[13] Abdel-Khalek AM. The Arabic Scale of Happiness (ASH): Psychometric characteristics. Compr Psychol 2013; 2: 5.

[http://dx.doi.org/10.2466/02.09.CP.2.5]

[14] Abdel-Khalek A, Alansari B. Happiness rate and its association with well-being and religiosity in a sample of college students from Kuwait university. J Edu Psychol Sci 2019; 1(20): 41-70.

[15] Abdel-Khalek A, Singh A. Love of life, happiness, and religiosity in Indian college students. Ment Health Relig Cult 2019; 22(8): 769-78. [http://dx.doi.org/10.1080/13674676.2019.1644303]

[16] Abdel-Khalek AM, Tekke M. The association between religiosity, well-being, and mental health among college students from Malaysia. Rev Mex Psicol 2019; 36(1): 5-16.

[17] Hills P, Argyle M. The Oxford Happiness Questionnaire: A compact scale for the measurement of psychological well-being. Pers Individ Dif 2002; 33: 1073-82

[http://dx.doi.org/10.1016/S0191-8869(01)00213-6]

[18] Baqer G. Relationship between happiness and personality variables. Eur Psychiatry 2016; 33: S210.

[http://dx.doi.org/10.1016/j.eurpsy.2016.01.502]

[19] Diener E, Suh EM, Lucas RE, Smith HL. Subjective well-being: Three decades of progress. Psychol Bull 1999; 125: 276-302. 
[http://dx.doi.org/10.1037/0033-2909.125.2.276]

[20] Pavot W, Diener E. The satisfaction with life scale and the emerging construct of life satisfaction. J Posit Psychol 2008; 3: 137-52. [http://dx.doi.org/10.1080/17439760701756946]

[21] Diener E, Emmons RA, Larsen RJ, Griffin S. The satisfaction with life scale. J Pers Assess 1985; 49(1): 71-5.

[http://dx.doi.org/10.1207/s15327752jpa4901 13] [PMID: 16367493]

[22] Abdallah T. The satisfaction with life scale (SWLS): Psychometric properties in an Arabic-speaking sample. Int J Adolesc Youth 1998; 7: 113-9.

[http://dx.doi.org/10.1080/02673843.1998.9747816]

[23] Diener E, Diener M. Cross-cultural correlates of life satisfaction and self-esteem.Culture and well-being: The collected works of ED Diener, Social Indicators Research Series. 2009; 38: pp. 71-91. [http://dx.doi.org/10.1007/978-90-481-2352-0_4]

[24] Durak M, Senol-Durak E, Gencoz T. Psychometric properties of the satisfaction with life scale among Turkish university students, correctional officers, and elderly adults. Soc Indic Res 2010; 99: 413-29.

[http://dx.doi.org/10.1007/s11205-010-9589-4]

[25] Al-Darmaki F, Hassane S, Ahammed S, Abdullah A, Dodeen H. Validation of arabic state self-esteem and satisfaction with life scale among married individuals from the united arab emirates. Int $\mathrm{J}$ Humanit Soc Sci 2015; 5(11): 76-83.

[26] Beck AT, Ward CH, Mendelson M, Mock J, Erbaugh J. An inventory for measuring depression. Arch Gen Psychiatry 1961; 4: 561-71. [http://dx.doi.org/10.1001/archpsyc.1961.01710120031004] [PMID: 13688369]

[27] Byrne BM. Structural equation modeling with AMOS: Basic concepts, applications, and programming. 2ed.. Washington, D.C: Routledge Academic. 2010.

[28] Hu L, Bentler PM. Fit indices in covariance structure modeling: Sensitivity to underparameterized model misspecification. Psychol Methods 1998; 3: 424-53.

[http://dx.doi.org/10.1037/1082-989X.3.4.424]

[29] MacCallum RC, Browne MW, Sugawara HM. Power analysis and determination of sample size for covariance structure modeling. Psychol Methods 1996; 1(2): 130-49.

[http://dx.doi.org/10.1037/1082-989X.1.2.130]

[30] Raykov T, Marcoulides GA. On multilevel reliability estimation from the perspective of structural equation modeling. Struct Equ Modeling 2006; 13: 130-41.

[http://dx.doi.org/10.1207/s15328007sem1301 7]

[31] Schumacker R, Lomax R. A beginner's guide to structural equation modeling. 2nd ed. Mahwah, NJ: Lawrence Erlbaum 2004. [http://dx.doi.org/10.4324/9781410610904]

[32] Chang SJ, Witteloostuijn A, Eden L. From the editors: Common method variance in international business research. J Int Bus Stud 2010; 41(2): 178-84.

[33] Happiness Westley D. The UAE's Happiest People Are...WhichSchoolAdvisor 2018.https://whichschooladvisor.com/

[34] Helliwell J, Layard R, Sachs J. World happiness report 2017. In: Sustainable Development Solutions Network. New York 2017.

\section{2021 Dodeen \& Cody.}

This is an open access article distributed under the terms of the Creative Commons Attribution 4.0 International Public License (CC-BY 4.0), a copy of which is available at: https://creativecommons.org/licenses/by/4.0/legalcode. This license permits unrestricted use, distribution, and reproduction in any medium, provided the original author and source are credited. 